\title{
Concordance of ATM (Ataxia Telangiectasia Mutated) Immunohistochemistry between Biopsy or Metastatic Tumor Samples and Primary Tumors in Gastric Cancer Patients
}

\author{
Hee Sung Kim ${ }^{e}$ Min A Kim ${ }^{a}$ Darren Hodgson ${ }^{f}$ Christopher Harbron ${ }^{f}$ \\ Robert Wellings $^{f}$ Mark J. O'Connor ${ }^{f}$ Christopher Womack $^{f}$ Lucy Yin $^{g}$ \\ Yung-Jue Bang ${ }^{b, d}$ Seok-Ah Im ${ }^{\text {b,d }}$ Byung Lan Lee ${ }^{c}$ Woo Ho Kim ${ }^{\text {a,d }}$ \\ ${ }^{\mathrm{a}}$ Department of Pathology, Seoul National University Hospital, Departments of ${ }^{\mathrm{b}}$ Internal Medicine and ${ }^{\mathrm{c}}$ Anatomy, \\ and ${ }^{\mathrm{d} C a n c e r}$ Research Institute, Seoul National University College of Medicine, Seoul, and ${ }^{\text {Department of }}$ \\ Pathology, Gachon University School of Medicine, Incheon, Korea, ${ }^{f}$ AstraZeneca, Alderley Park, Macclesfield, UK, \\ and 9 Innovation Center China, AstraZeneca, Zhangjiang Hi-Tech Park, Shanghai, PR China
}

\section{Key Words}

Ataxia telangiectasia mutated protein - Biopsy · Immunohistochemistry · Metastatic tumor · Stomach neoplasm

\begin{abstract}
ATM (ataxia telangiectasia mutated) is one of several DNA repair proteins that are suggested to sensitize tumor cells to the poly(ADP-ribose) polymerase inhibitor olaparib when deficient. The aim of this study was to assess the spatiotemporal concordance of ATM immunohistochemistry $(\mathrm{IHC})$ in gastric cancer in order to determine if measurements made at the level of various sample types and times could be inferred as having the potential to be relevant to treatment decisions made at the patient level. Two independent cohorts composed of 591 gastric cancer patients divided into a gastrectomy cohort $(n=450)$ and a metastasis cohort $(n=$ 141) were used in this study. A total of 2,705 ATM IHC samples were examined, including 450 whole tissue, 3 sets of 450 tissue microarray (TMA), 301 biopsy, 222 metastatic tumor and 2 additional whole tissue samples of 50 cases from the gastrectomy cohort, and 141 pairs of primary and metastatic tumors from the metastasis cohort. The prevalence of ATM
\end{abstract}

negativity was $13.1 \%$ in biopsies, $13.9,15.1$, and $16.0 \%$ in TMAs and $15.9 \%$ in whole tissue samples of the gastrectomy cohort, and $21.4 \%$ in primary tumor and $21.5 \%$ in metastatic tumor samples of the metastasis cohort. $\mathrm{k}$ coefficients were 0.341 for biopsy, 0.572 as the average of 3 TMAs and 0.415 for the largely synchronous metastatic tumors of the gastrectomy cohort, and 0.153 for the largely asynchronous metastatic tumors of the metastasis cohort. Using whole tissue sections from tumor resections or primary tumor, respectively, as the reference standards, specificity and sensitivity were 91.6 and $41.0 \%$ for biopsy, 93.9 and $61.9 \%$ as the average of 3 TMAs, and 86.6 and $58.8 \%$ for metastatic tumors of the gastrectomy cohort and 81.7 and $33.3 \%$ for metastatic tumors of the metastasis cohort, respectively. Although we have demonstrated that the IHC assay for ATM was robust and reproducible in gastric tumor samples, we have also found that measurements were subject to significant discordance across multiple sample types from the same patient. Further work will be necessary to determine if classification may be made more consistent by multiple sampling. However, the lack of agreement between primary and asynchronous metastatic samples suggests that such sampling would need to be performed at the time of any treatment decision.

Copyright $\odot 2013$ S. Karger AG, Basel

Woo Ho Kim

Department of Pathology, Seoul National University College of Medicine 28 Yeongeon-dong

Jongno-gu, Seoul 110-799 (Korea)

E-Mail woohokim@snu.ac.kr 


\section{Introduction}

Gastric cancer is the fourth most common cancer worldwide with approximately 1 million new cases diagnosed per year, and it remains the second most common cause of cancer-related death worldwide [1]. Gastric cancer is a heterogeneous disease. Tissue samples of pretreatment biopsies are a valuable resource for translational research aiming towards the identification of predictive biomarkers for the selection of patients who are likely to benefit from systemic therapy designed for metastatic gastric cancer.

ATM (ataxia telangiectasia mutated) is a protein kinase that regulates cell cycle checkpoints, and DNA repair and recombination. ATM, which is essential for homologous recombination repair in response to DNA double-strand break (DSB) damage, interacts with and regulates NBS1 (Nijmegen breakage syndrome 1) and the BRCA complex [2]. Moreover, ATM mutant cells exhibit impaired DNA DSB repair. These observations suggest that tumor cells with defective ATM expression or activity leading to homologous recombination deficiency are likely to be more sensitive to the targeted therapeutic/chemotherapeutic agents that cause the accumulation of DNA DSBs during replication.

Poly(ADP-ribose) polymerase (PARP-1) is a nuclear enzyme which is activated in response to genotoxic insults by binding damaged DNA and attaching polymers of ADP-ribose to nuclear proteins at the expense of its substrate NAD+. The protein responds to DNA damage by transferring 50-200 molecules of ADP-ribose to various nuclear proteins, including transcription factors, histones and PARP-1 itself. This poly(ADP-ribosyl)ation activity of PARP-1 appears to be important for maintaining genomic integrity [3]. ATM and PARP-1 are two of the most important players in the response of cells to DNA damage.

The potent oral inhibitor PARP olaparib has selective antitumor activity in cancers associated with breast cancer (BRCA1 and BRCA2) mutations [4] and is hypothesized to be effective in tumors whose DNA repair mechanisms are compromised (i.e., that have homologous recombination repair deficiency). ATM gene mutations contribute to various B- and T-cell leukemias, and 20$50 \%$ of mantle cell lymphoma cases contain mutations in ATM [5]. PARP inhibition, which imposes the requirement for DNA DSB repair, should selectively sensitize ATM-deficient tumor cells to killing [6], and olaparib induces significant killing of ATM-deficient lymphoid tumor cells in vitro and in vivo [7].

ATM gene mutations were detected in gastric cancer cell lines and primary gastric cancer specimens [8]. Five nucleotide variations were identified in primary gastric cancer tissue. ATM mRNA and protein levels were found to be decreased in gastric cancers compared to normal samples, phosphorylated ATM was consistently present in gastric cancers, and low levels of phosphorylated ATM were significantly correlated with poor differentiation, lymph node metastasis and poor 5-year survival [9]. Guo et al. [10] observed that ATM deficiency sensitizes cells to the growth-inhibitory effects of olaparib and SN-38 (the active metabolite of irinotecan) in gastric cancer cells with reduced ATM expression.

There is an increasing demand for the development of biomarkers for cancer detection in biopsy samples, and optimal tumor sampling is one of the most important prerequisites for the reliability of biomarker reporting due to tumor heterogeneity. The most recent set of guidelines of the American Society of Clinical Oncology-College of American Pathologists states, 'large, preferably multiple core biopsies of tumor are preferred for testing if they are representative of the tumor (grade and type) at resection' [11]. Several studies assessing the concordance in tissue immunohistochemistry (IHC) from different areas of the same tumor by using tissue microarrays (TMAs) have used positively expressed proteins such as estrogen and progesterone receptors, HER2, Ki-67, and p53 [12], but only a few proteins showing loss of expression or tumor suppressor proteins such as $\mathrm{pRb}$ [12] and E-cadherin [13] have been used. Although some studies ascertain the concordance rate of differently sized specimens $[12,14,15]$, there is no concordance study between biopsy specimens and subsequent primary resection specimens with regard to tumor suppressor proteins.

We examined spatiotemporal concordance of these specimens to determine ATM by IHC in order to assess the validity of this marker as a candidate predictive marker for the treatment of patients with metastatic gastric cancer with the PARP inhibitor olaparib.

\section{Patients and Methods}

\section{Cohort Description}

Two independent cohorts were used for this study, both of them were from the tissue archives of the Seoul National University Department of Pathology. The gastrectomy cohort consisted of 450 consecutive gastric cancer patients who underwent gastrectomy between 1 January 2004 and 31 December 2004 at the Seoul National University Hospital. The patients included 327 men and 123 women with a mean age of 57.5 years. The gastric cancers consisted of 170 early gastric cancers and 280 advanced gastric cancers. Histologic type was classified as intestinal in 185 , diffuse in 185 , mixed in 77 and undetermined in 3 cases on the basis of Lauren's 
classification. The tumor was located in the upper third in 83 , middle third in 126, lower third in 221 and the entire stomach in 20 cases. One hundred ninety-nine patients were diagnosed as stage I, 87 as stage II, 82 as stage III and 82 as stage IV.

As the gastrectomy cohort was previously studied for heterogeneous HER2 amplification [16], we compared the concordance among HER2 amplification by FISH, HER2 overexpression by IHC and ATM loss by IHC in 3 TMAs.

The metastasis cohort consisted of 141 gastric cancer patients with paired primary and metastatic tumors. The patients underwent surgical $(n=112)$ or endoscopic biopsy $(n=29)$ between 1989 and 2006 at the Seoul National University Hospital. The metastatic tumor was asynchronous in 71 and synchronous in 70 cases. All the patients were diagnosed as adenocarcinoma of the stomach, and none of them received chemotherapy or radiation therapy prior to resection. This study was approved by the Institutional Review Board of the Seoul National University Hospital (H-1010-065-336). Standard histopathological examination included assessment of cancer type and pathological tumor stage according to the criteria established by the 6th edition of the Staging Manual of the American Joint Committee on Cancer [17].

\section{Patient Samples and TMA Construction}

For the gastrectomy cohort, 3 core tissue specimens (diameter $2 \mathrm{~mm}$ ) were obtained from individual paraffin-embedded gastric cancer tissue samples (donor blocks) and arranged in 3 sets of new recipient paraffin blocks (tissue array blocks) using a trephine apparatus (Superbiochips Laboratories, Seoul, Korea). Each TMA block contained up to 60 cores. Three sets of 8 TMA blocks were prepared during the study. Whole tissue sections from all 450 cases in the gastrectomy cohort were obtained. Corresponding preoperative endoscopic biopsy specimens from 301 cases and metastatic tumor specimens from 222 cases were obtained from the archives of the Pathology Department of the Seoul National University. For 115 cases, both biopsy and metastatic tissues were available. An additional 2 paraffin blocks were selected for 50 cases, among which the original whole tissue was ATM negative in 20 and ATM positive in 30, to study intratumoral heterogeneity.

In the 2 cohorts, 363 patients had paired primary and metastatic tumor tissues. These consisted of 222 cases from the gastrectomy cohort and 141 cases from the metastasis cohort; 284 were synchronous (214 from the gastrectomy cohort and 70 from the metastasis cohort) and 79 were asynchronous ( 8 from the gastrectomy cohort and 71 from the metastasis cohort) tumors. The metastatic tumor sample type was TMA in 214, biopsy in 7, and whole tissue section in 1 case in the gastrectomy cohort, and TMA in 48 , biopsy in 70, and whole tissue section in 23 cases in the metastasis cohort. The metastatic tumor organs were lymph node, liver, abdominal cavity, colon, stomach, uterus, vagina, skin, lung, pancreas, bone, adrenal gland, breast, diaphragm, gallbladder, pelvic cavity and urinary tract.

\section{Immunohistochemistry}

Five commercial antibodies for ATM were evaluated using cell and formalin-fixed paraffin-embedded human cancer TMAs. The antibody providing best discrimination in staining between transfected and nontransfected ATM cells was the rabbit monoclonal antibody (clone Y170 obtained from Epitomics, Burlingame, Calif., USA), which was raised to a peptide around amino acid residue Ser ${ }^{1981}$. The overall superiority of this Epito- mics antibody was confirmed by informatics analysis of the cancer TMAs. It provided evidence of biomarker utility in triplenegative breast carcinoma compared with lobular-type breast carcinoma. In addition, it was suitable for use in a 1-day partially automated staining protocol. Therefore, the Epitomics antibody was considered to be the ATM antibody of choice for inclusion in this IHC biomarker panel of homologous recombination repair deficiency.

A standard operating procedure for the immunohistochemical staining of ATM was established using formalin-fixed paraffin-embedded sections of human tissue. In summary, serial sections ( $4 \mu \mathrm{m}$ thick) from blocks were dewaxed in xylene and rehydrated using a graded alcohol series. For the antigen retrieval step, slides were inserted in a rack in diluted target retrieval solution, $\mathrm{pH} 6.0$ (EDTA), and preheated to $100^{\circ} \mathrm{C}$ for $6 \mathrm{~min}$, and then further heated at $1,000 \mathrm{~W}$ for $5 \mathrm{~min}$. The slides were then transferred to the Autostainer 360 (Lab Vision, Kalamazoo, Mich., USA) and the program was run as follows: (1) slides were rinsed in wash buffer peroxidase blocking solution, (2) incubated with primary antibody: anti-ATM antibody (rabbit, monoclonal, Y170; Epitomics) for $60 \mathrm{~min}$, (3) labelled with polymer for $8 \mathrm{~min}$ and (4) incubated with DAB (Envision kit; DAKO, Glostrup, Denmark) for $10 \mathrm{~min}$, and then counterstained in Mayer's hematoxylin.

\section{Interpretation}

As a positive control for sections, lymphocytes in the mantle and paracortical tonsil areas should show strong nuclear staining. In the germinal centers, variable nuclear staining may be observed. Cancer cells showing nuclear staining, regardless of the presence of cytoplasmic staining, were considered positively immunostained for ATM. Intensity was graded as 0 (totally negative), \pm (equivocal staining, signal observed only at high-power microscopy with $\times 40$ eyepiece), $+/ 3$ (weak positive), $++/ 3$ (moderately positive) and $+++/ 3$ (strongly positive, almost equal to lymphocytes and neutrophils). The criteria for negative cases were set as less than $10 \%$ of cells stained as weak positive $(+/ 3)$ or higher intensity, that is, more than $90 \%$ of cells showing totally negative (0) or equivocal staining $( \pm)$. For example, if more than $90 \%$ of tumor cells showed equivocal $( \pm)$ or negative $(0)$ staining and less than $10 \%$ showed any positive $(+,++$ or $+++/ 3)$ staining, a case was defined as negative (fig. 1).

All the scores were performed using eye scoring under conventional light microscopy. Two pathologists (H.S.K. and W.H.K.) both scored 450 individual TMA spots until interreader reproducibility was confirmed, and then one pathologist (H.S.K.) scored the remainder.

\section{Concordance between Laboratories and Pathologists}

Concordances, both between laboratories of ICC (Innovation Center China, AstraZeneca) and SNUH (Department of Pathology, Seoul National University) and between pathologists (L.Y. and W.H.K.), for negative and positive staining in surgical samples as well as biopsy samples were analyzed. The reproducibility of interpretation was confirmed by concordance analysis.

\section{Statistical Analysis}

Prevalence would be defined as the proportion of patients who could be reproducibly identified as having tumors demonstrating ATM loss by IHC. However, here we have measured the prevalence of tumor samples demonstrating ATM loss by IHC. Then 

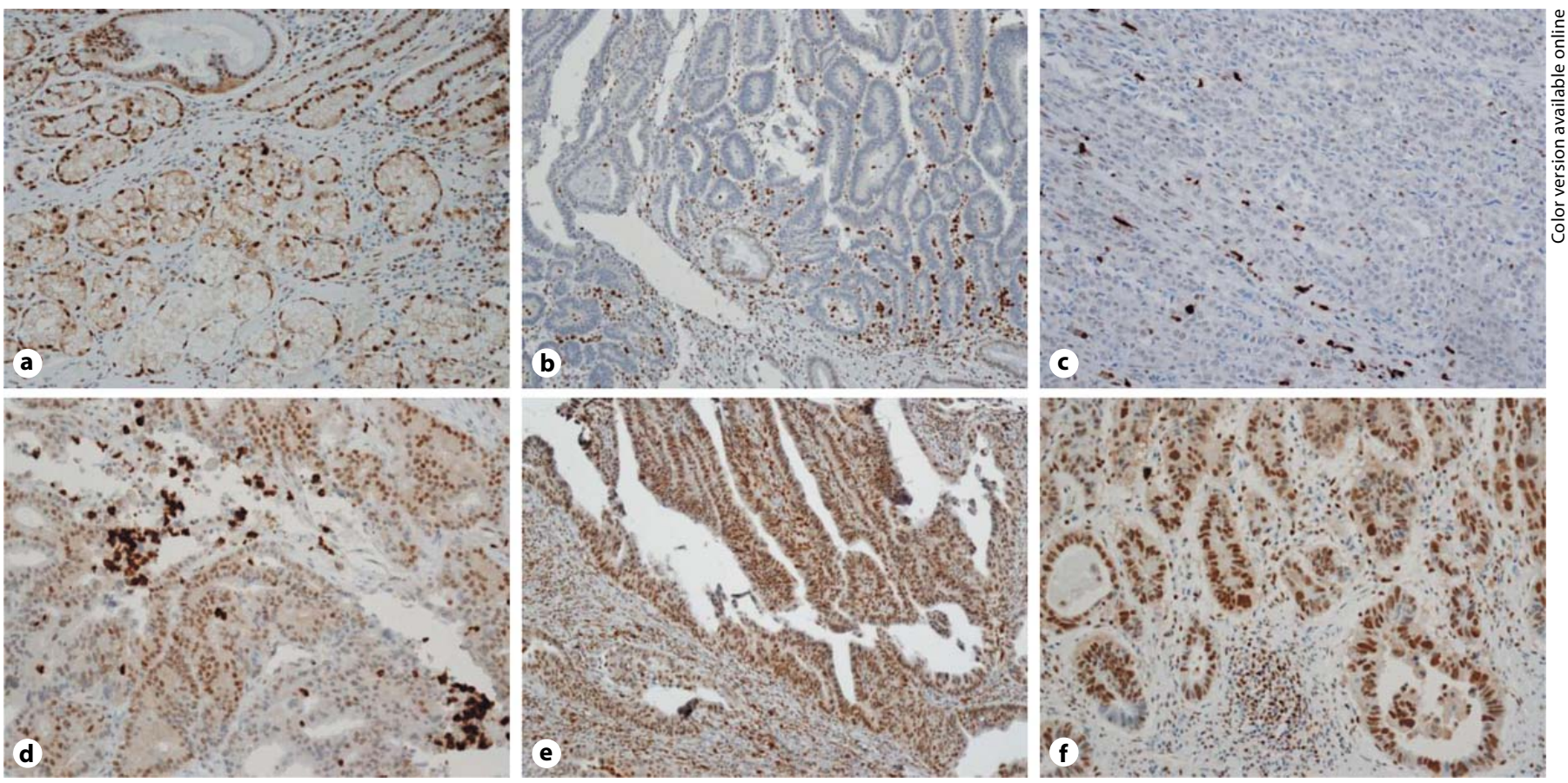

Fig. 1. ATM IHC in human gastric tissue. a Immunostaining of normal gastric mucosa revealed moderately positive nuclear staining in epithelial cells. b-f Representative cases of gastric cancer tissue showing each intensity of scoring criteria for ATM IHC:

we looked at agreement between two sample types from the same patient. The term agreement refers to the percent of patients for whom the measurements on two samples agree. It is heavily influenced by prevalence. Therefore, we used Cohen's $\kappa$ statistics as a measure of agreement. Reasons for nonagreement may be technical or biological. In a pilot study, technical reproducibility was initially examined by staining sections from the same tumor biopsies at two independent laboratories using the same standard operating procedure (SOP). We then went on to examine agreement across different sample sets from the same patients in the same laboratory. A $\kappa$ statistic of 1 implies perfect agreement whilst a $\kappa$ of 0 implies a random relationship between the results from the two samples being compared. Interpretation of intermediate values of the $\kappa$ statistic have been discussed by Landis and Koch [18] as follows: $<0.00$, poor; $0.00-0.20$, slight; $0.21-0.40$, fair; $0.41-$ 0.60 , moderate; $0.61-0.80$, substantial, and $0.81-1.00$, almost perfect. The ultimate intent of this study would be to identify patients with tumors showing ATM loss; sensitivity describes the percentage of those patient samples in the sample set showing ATM loss by IHC using a defined gold standard (whole tissue or primary tumors) which are also identified as showing ATM loss by the other measurement. Similarly, specificity describes the percentage of those patient samples in the sample set showing ATM presence using a defined gold standard (whole tissue or primary tumors) which also demonstrated ATM presence by the other measurement. To measure agreement between data sets, $\kappa$ and intraclass correlation coefficients were calculated using SPSS software, version 15.0 (SPSS Inc., Chicago, Ill., USA). negative $(0 ; \mathbf{b})$, equivocal $( \pm ; \mathbf{c})$, weak $(+; \mathbf{d})$, moderate $(++; \mathbf{e})$ and strong $(+++; \mathbf{f})$ scoring. Lymphocytes were strongly positive and used as internal control.

\section{Results}

\section{Clinicopathological Correlation of ATM Expression and Gastric Cancer}

Nonneoplastic gastric mucosa or intestinal metaplasia showed positive nuclear staining of ATM protein. Nuclear staining was noted in stromal cells such as lymphocytes, fibroblasts, endothelial cells and smooth muscle tissues. Loss of nuclear staining was limited to malignant epithelium.

ATM loss in gastric cancer was significantly correlated with female gender, larger tumor size $(\geq 4 \mathrm{~cm})$ and presence of venous invasion. There was a borderline significant correlation between older age ( $\geq 60$ years) and ATM loss. No significant correlation was noted between ATM loss and histological type or TNM stage of gastric cancer (table 1). There was no significant difference in overall or disease-free survival according to ATM expression in gastric cancer (data not shown).

\section{Reproducibility of the ATM IHC Assay between Independent Laboratories}

Independently, 50 gastric cancer archives, which consisted of the same 25 whole tissue and 25 biopsy samples, 
were stained and interpreted according to SOP at two laboratories: ICC and SNUH (table 2). Because the staining results of whole tissue and biopsy samples were not available for 1 patient, concordance was analyzed using the results of 24 whole tissue and 24 biopsy samples. ATM loss by IHC was detected in 5 of 24 (20.8\%) surgical samples, and 2 of $24(8.3 \%)$ biopsy samples in ICC, and 5 of $24(20.8 \%)$ surgical samples and 4 of 24 (16.6\%) biopsy samples in SNUH (agreement $=100 \%$ for whole tissue, $91.7 \%$ for biopsy; $\kappa=1.000$ for whole tissue, $\kappa=0.625$ for biopsy; table 1). The results confirmed the reproducibility of the methods described in the SOP prior to executing the larger population study.

\section{ATM Negativity in Various Samples of Gastric Cancer}

In the gastrectomy cohort, ATM negativity was $15.9 \%$ (71/447) in the whole tissue; $13.1 \%(35 / 268)$ in biopsy; $15.1 \%$ (65/430), $16.0 \%(65 / 406)$ and $13.9 \%(60 / 433)$ in TMAs, and $21.2 \%(42 / 198)$ in metastatic tumor samples (table 3). In the metastasis cohort, ATM negativity was $21.4 \%(30 / 140)$ in the primary tumor and $21.5 \%(26 / 121)$ in the metastatic tumor. The specificity and sensitivity of various samples were calculated using whole tissue in the gastrectomy cohort and primary tumor in the metastasis cohort as gold standard or reference. Sensitivity and specificity were 41.0 and $91.6 \%$ for biopsy; 57.4-64.6 and 92.8-95.6\% for TMAs; 58.8 and $86.6 \%$ for metastatic tissue in the gastrectomy cohort, and 33.3 and $81.7 \%$ in the metastasis cohort. The $\kappa$ coefficient was 0.341 for biopsy, 0.510-0.626 for TMAs and 0.415 for metastatic tissue in the gastrectomy cohort, and 0.153 for metastatic tissue in the metastasis cohort. From the two cohorts, 244 synchronous and 75 asynchronous metastatic tissues were comparable to corresponding primary tissue. The $\kappa$ coefficients were 0.387 for synchronous and 0.065 for asynchronous metastatic tissue.

We applied alternative scoring criteria defining ATM loss as more than $80 \%$ of cells with negative staining and recalculated the concordance rates across different sample types (table 3). Redefining ATM loss with a less stringent definition did not increase the observed concordance. Similar levels of concordance were observed varying the threshold used to define negativity over a wider range of values.

\section{Heterogeneity of ATM IHC among 3 TMAs and 3 \\ Paraffin Blocks of Primary Gastric Cancer}

ATM IHC of TMAs sampled from 3 different areas of primary tumors of the gastrectomy cohort was compared to whole tissue samples. In 380 cases, the 3 TMAs and
Table 1. Association between clinicopathological variables and ATM expression in gastric cancer

\begin{tabular}{|c|c|c|c|c|c|c|c|}
\hline & \multicolumn{2}{|c|}{ Total } & \multicolumn{2}{|c|}{$\begin{array}{l}\text { ATM } \\
\text { negative }\end{array}$} & \multicolumn{2}{|c|}{$\begin{array}{l}\text { ATM } \\
\text { positive }\end{array}$} & \multirow[t]{2}{*}{$\mathrm{p}$} \\
\hline & $\mathrm{n}$ & $\%$ & $\mathrm{n}$ & $\%$ & $\mathrm{n}$ & $\%$ & \\
\hline Total & 447 & 100 & 71 & 16 & 376 & 84 & \\
\hline \multicolumn{8}{|l|}{ Gender } \\
\hline Male & 324 & 72 & 44 & 14 & 280 & 86 & 0.031 \\
\hline Female & 123 & 28 & 27 & 22 & 96 & 78 & \\
\hline \multicolumn{8}{|l|}{ Age } \\
\hline$<60$ years & 227 & 51 & 29 & 13 & 198 & 87 & 0.068 \\
\hline$\geq 60$ years & 220 & 49 & 42 & 19 & 178 & 81 & \\
\hline \multicolumn{8}{|l|}{ Location } \\
\hline Upper & 82 & 18 & 12 & 15 & 70 & 85 & 0.544 \\
\hline Middle & 126 & 28 & 17 & 13 & 109 & 87 & \\
\hline Lower & 218 & 49 & 40 & 18 & 178 & 82 & \\
\hline Entire & 20 & 4 & 2 & 10 & 18 & 90 & \\
\hline \multicolumn{8}{|l|}{ Lauren } \\
\hline Intestinal & 184 & 41 & 32 & 17 & 152 & 83 & 0.592 \\
\hline Diffuse & 183 & 41 & 25 & 14 & 158 & 86 & \\
\hline Mixed & 77 & 17 & 13 & 17 & 64 & 83 & \\
\hline \multicolumn{8}{|l|}{ Ming } \\
\hline Infiltrative & 396 & 89 & 63 & 16 & 333 & 84 & 0.967 \\
\hline Expanding & 51 & 11 & 8 & 16 & 43 & 84 & \\
\hline \multicolumn{8}{|l|}{ Size } \\
\hline$<4 \mathrm{~cm}$ & 161 & 36 & 17 & 11 & 144 & 89 & 0.021 \\
\hline$\geq 4 \mathrm{~cm}$ & 286 & 64 & 54 & 19 & 232 & 81 & \\
\hline \multicolumn{8}{|l|}{ EGC or AGC } \\
\hline AGC & 320 & 72 & 54 & 17 & 266 & 83 & 0.363 \\
\hline EGC & 127 & 28 & 17 & 13 & 110 & 87 & \\
\hline \multicolumn{8}{|l|}{ Lymph node } \\
\hline Negative & 189 & 42 & 26 & 14 & 163 & 86 & 0.292 \\
\hline Positive & 258 & 58 & 45 & 17 & 213 & 83 & \\
\hline \multicolumn{8}{|l|}{ M stage } \\
\hline M0 & 393 & 88 & 63 & 16 & 330 & 84 & 0.819 \\
\hline M1 & 54 & 12 & 8 & 15 & 46 & 85 & \\
\hline \multicolumn{8}{|l|}{ TNM stage } \\
\hline I & 196 & 44 & 28 & 14 & 168 & 86 & 0.837 \\
\hline II & 87 & 20 & 15 & 17 & 72 & 83 & \\
\hline III & 82 & 18 & 15 & 18 & 67 & 82 & \\
\hline IV & 82 & 18 & 13 & 16 & 69 & 84 & \\
\hline \multicolumn{8}{|l|}{ Lymphatic invasion } \\
\hline Not identified & 185 & 41 & 28 & 15 & 157 & 85 & 0.716 \\
\hline Present & 262 & 59 & 43 & 16 & 219 & 84 & \\
\hline \multicolumn{8}{|l|}{ Venous invasion } \\
\hline Not identified & 370 & 83 & 52 & 14 & 318 & 86 & 0.020 \\
\hline Present & 77 & 17 & 19 & 25 & 58 & 75 & \\
\hline \multicolumn{8}{|l|}{ Perineural invasion } \\
\hline Not identified & 231 & 52 & 41 & 18 & 190 & 82 & 0.265 \\
\hline Present & 216 & 48 & 30 & 14 & 186 & 86 & \\
\hline \multicolumn{8}{|l|}{ Recurrence } \\
\hline No recurrence & 305 & 68 & 49 & 16 & 256 & 84 & 0.986 \\
\hline Recurred & 96 & 22 & 15 & 16 & 81 & 84 & \\
\hline No R0 resection & 46 & 10 & 7 & 15 & 39 & 85 & \\
\hline
\end{tabular}

$\mathrm{EGC}=$ Early gastric cancer; AGC = advanced gastric cancer. 
Table 2. Interlaboratory concordance of IHC for ATM using 25 whole tissue and 25 biopsy samples in a pilot study

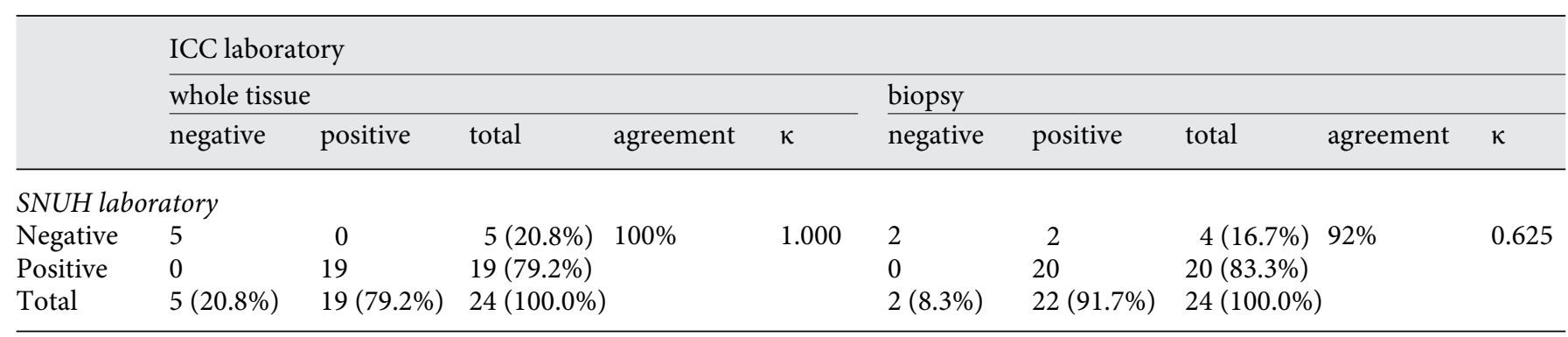

Results were unavailable from 1 whole tissue sample and 1 biopsy sample.

Table 3. Accuracy of ATM IHC in various samples from two cohorts of gastric cancer by two different scoring criteria for ATM loss

\begin{tabular}{|c|c|c|c|c|c|c|c|c|c|c|c|c|}
\hline \multirow[t]{2}{*}{ Cohort } & \multirow[t]{2}{*}{ Sample } & \multirow[t]{2}{*}{$\begin{array}{l}\text { Total } \\
\mathrm{n}\end{array}$} & \multicolumn{5}{|c|}{$\begin{array}{l}\text { Criteria defining ATM loss as } \geq 90 \% \text { negative } \\
\text { cells }\end{array}$} & \multicolumn{5}{|c|}{$\begin{array}{l}\text { Criteria defining ATM loss as } \geq 80 \% \text { negative } \\
\text { cells }\end{array}$} \\
\hline & & & $\begin{array}{l}\text { ATM } \\
\text { negativity }\end{array}$ & $\begin{array}{l}\text { specifi- } \\
\text { city }^{b}\end{array}$ & $\begin{array}{l}\text { sensiti- } \\
\text { vity }^{\mathrm{a}}\end{array}$ & $\begin{array}{l}\text { agree- } \\
\text { ment, } \\
\%^{c}\end{array}$ & $\kappa^{\mathrm{d}}$ & $\begin{array}{l}\text { ATM } \\
\text { negativity }\end{array}$ & $\begin{array}{l}\text { specifi- } \\
\text { city }^{b}\end{array}$ & $\begin{array}{l}\text { sensiti- } \\
\text { vity }^{\mathrm{a}}\end{array}$ & $\begin{array}{l}\text { agree- } \\
\text { ment, } \\
\%^{c}\end{array}$ & $\kappa^{\mathrm{d}}$ \\
\hline \multirow[t]{6}{*}{ Gastrectomy } & Whole tissue & 450 & $15.9(71 / 447)$ & & & & & $17.0(76 / 447)$ & & & & \\
\hline & Biopsy & 301 & $13.1(35 / 268)$ & 91.6 & 41.0 & 84 & 0.341 & $13.4(36 / 268)$ & 91.1 & 38.1 & 83 & 0.310 \\
\hline & TMA (A) & 450 & $15.1(65 / 430)$ & 92.8 & 57.4 & 87 & 0.510 & $24.2(104 / 430)$ & 84.7 & 68.5 & 82 & 0.456 \\
\hline & TMA (B) & 450 & $16.0(65 / 406)$ & 93.3 & 64.6 & 89 & 0.579 & $26.8(109 / 406)$ & 83.1 & 75.4 & 82 & 0.475 \\
\hline & TMA (C) & 450 & $13.9(60 / 433)$ & 95.6 & 63.8 & 90 & 0.626 & $24.0(104 / 433)$ & 85.1 & 68.9 & 82 & 0.466 \\
\hline & Metastasis & 222 & $21.2(42 / 198)$ & 86.6 & 58.8 & 82 & 0.415 & $36.4(72 / 198)$ & 70.6 & 68.6 & 70 & 0.276 \\
\hline \multirow[t]{2}{*}{ Metastasis } & Primary & 141 & $21.4(30 / 140)$ & & & & & $22.1(31 / 140)$ & & & & \\
\hline & Metastasis & 141 & $21.5(26 / 121)$ & 81.7 & 33.3 & 71 & 0.153 & $22.3(27 / 121)$ & 80.6 & 33.3 & 70 & 0.140 \\
\hline \multirow{3}{*}{$\begin{array}{l}\text { Gastrectomy } \\
\text { and metasta- } \\
\text { sis cohorts }\end{array}$} & Metastasis & 363 & $21.4(68 / 318)$ & 87.2 & 42.6 & 78 & 0.310 & $31.1(99 / 318)$ & 86.8 & 33.3 & 70 & 0.224 \\
\hline & Synchronous & 284 & $21.3(52 / 244)$ & 89.0 & 48.1 & 80 & 0.387 & $34.0(83 / 244)$ & 88.8 & 34.9 & 70 & 0.265 \\
\hline & Asynchronous & 79 & $21.3(16 / 75)$ & 81.4 & 25.0 & 69 & 0.065 & $21.3(16 / 75)$ & 81.4 & 25.0 & 69 & 0.065 \\
\hline
\end{tabular}

a-d Sensitivity, specificity and agreement was calculated using whole sections in the gastrectomy cohort and primary tumor in the metastasis cohort as gold standard or reference.

whole tissue samples were comparable. Concordantly negative staining in 3 cores was detected in 30 (7.9\%) cases, among which the whole tissue was negative in 27 and positive in 3 cases. Concordantly positive staining in 3 cores was found in 296 (77.9\%) cases, of which the whole tissue was positive in 280 and negative in 16 cases. Heterogeneous staining in 1 or 2 negative cores was seen in $54(14.2 \%)$ cases, of which the whole tissue was negative in 18 and positive in 36 cases (table 4).

In 50 cases, of which ATM was negative in 20 and positive in 30 cases, an additional 2 paraffin blocks were immunostained and compared to the original whole tissue. Three blocks were concordantly negative in 14 (28.0\%), concordantly positive in $26(52.0 \%)$ and discordant in 10 (20.0\%) cases (table 5).
Concordance of ATM IHC among Biopsy, TMA, Whole Tissue and Metastatic Tumor from the Same

\section{Gastric Cancer Patients}

We compared the ATM IHC of biopsy, TMA, whole tissue, primary tumor samples and metastatic tumor samples from the same patients in the two cohorts. Among 591 patients, 121 cases (100 patients in the gastrectomy cohort and 21 patients in the metastasis cohort) were incomparable because only 1 result was obtained, and 470 cases (350 patients from the gastrectomy cohort and 120 patients from the metastasis cohort) were compared for ATM IHC and scored as negative or positive (table 6). The inconsistent classification by biopsy was $17.8 \%$ in the biopsy versus whole tissue comparison, and $13.2 \%$ in the biopsy, whole tissue and metastatic tumor comparison. The inconsistent 
classification by metastatic tumor was $23.7 \%$ in the biopsy, whole tissue and metastatic tumor comparison; $10.7 \%$ in the whole tissue and metastatic tumor comparison; $29.2 \%$ in the metastasis cohort, and $22.3 \%$ in all patients from the two cohorts. Overall concordance rates were $82.2 \%$ in the biopsy and whole tissue comparison; $71.1 \%$ in the biopsy, whole tissue and metastatic tumor comparison; $89.3 \%$ in the whole tissue and metastatic tumor comparison, and $70.8 \%$ in the metastasis cohort.

A total of 318 metastatic tumors were assessed for ATM IHC from the two cohorts. ATM negativity was $21.4 \%(68 / 318)$ in all, and $21.3 \%(52 / 244)$ in synchronous and $21.3 \%(16 / 75)$ in asynchronous metastatic tumors.

\section{Heterogeneity of ATM Loss by IHC and HER2}

Overexpression in the Same TMAs

In order to analyze the degree of heterogeneity of ATM loss, we compared the proportion of concordant and discordant cases by ATM loss and HER 2 overexpression by IHC. In addition, because FISH is a standardized method to determine HER2 amplification for equivocal cases by IHC, we compared the degree of concordance with IHC results. A previous concordance study of HER2 IHC was carried out with the same TMAs used in the present study [15]. Discordant cases among TMAs were $14.2 \%$ for ATM IHC, $2.5 \%$ for HER2 FISH and $14.5 \%$ for HER2 IHC. Concordant target detection was $17.8 \%$ for HER2 IHC, $8.3 \%$ for HER2 FISH and 7.9\% for ATM IHC. The proportion of discordant cases to concordant target detection cases was calculated and this value, which is considered representative of the degree of heterogeneity of the protein with the method, was 1.80 for ATM IHC, 0.30 for HER2 FISH and 0.82 for HER2 IHC. Intraclass correlation coefficients among 3 TMAs were 0.604 for ATM loss by IHC, 0.904 for HER 2 amplification by FISH and 0.767 for HER2 overexpression by IHC (table 7).

\section{Discussion}

We confirmed the reproducibility of ATM IHC staining and scoring methods in two independent laboratories and established an SOP for ATM IHC and interpretation. This study was performed in a large population of gastric cancer patients to identify patients with tumors with ATM loss using the established SOP.

In Western countries, because most patients are diagnosed during advanced stages, less than $50 \%$ of these patients are amenable to curative surgical resection, and two thirds of them will experience recurrence within 2
Table 4. Heterogeneity of ATM IHC among 3 TMAs and whole tissue section

\begin{tabular}{lrlr}
\hline ATM in 3 TMAs & $\mathrm{n}$ & \multicolumn{2}{l}{ Whole tissue section } \\
\cline { 3 - 4 } & & negative & \multicolumn{1}{c}{ positive } \\
\hline All core(s) negative & 30 & $27(90.0 \%)$ & $3(10.0 \%)$ \\
All core(s) positive & 296 & $16(5.4 \%)$ & $280(94.6 \%)$ \\
2 negative, 1 positive & 24 & $10(41.7 \%)$ & $14(58.3 \%)$ \\
1 negative, 1 or 2 positive & 30 & $8(26.7 \%)$ & $22(73.3 \%)$ \\
\hline
\end{tabular}

Table 5. Heterogeneity of ATM IHC in gastric cancer among 3 paraffin blocks of a selected population of positives and negatives in a whole tissue section

\begin{tabular}{|c|c|c|c|}
\hline \multirow[t]{2}{*}{$\begin{array}{l}\text { ATM in } \\
3 \text { paraffin blocks }\end{array}$} & \multicolumn{2}{|c|}{$\begin{array}{l}\text { ATM in original whole } \\
\text { tissue }\end{array}$} & \multirow[t]{2}{*}{$\begin{array}{l}\text { Total } \\
(\mathrm{n}=50)\end{array}$} \\
\hline & $\begin{array}{l}\text { negative } \\
(\mathrm{n}=20)\end{array}$ & $\begin{array}{l}\text { positive } \\
(\mathrm{n}=30)\end{array}$ & \\
\hline \multicolumn{4}{|l|}{ Concordance } \\
\hline All 3 negative & $14(70.0 \%)$ & $0(0 \%)$ & $14(28.0 \%)$ \\
\hline All 3 positive & $0(0 \%)$ & $26(86.7 \%)$ & $26(52.0 \%)$ \\
\hline \multicolumn{4}{|l|}{ Discordance } \\
\hline 2 negative, 1 positive & $3(15.0 \%)$ & $2(6.7 \%)$ & $5(10.0 \%)$ \\
\hline 1 negative, 2 positive & $3(15.0 \%)$ & $1(3.3 \%)$ & $5(10.0 \%)$ \\
\hline
\end{tabular}

years. The introduction of multimodality treatments, neoadjuvant chemotherapy and postoperative chemoradiotherapy, as well as new chemotherapeutic regimens is still having a limited impact on relapse-free and overall survival of these patients [19]. The most cost-efficient and medically effective way to study stomach cancer biomarkers is to analyze them on the excisional specimen, because the larger tumor volume of the excisional biopsy helps avoid the problem of intratumoral heterogeneity. However, in biomarker studies of inoperable-stage gastric cancer patients, endoscopic biopsy or metastatic tumor specimens are preferable.

ATM deficiency has been shown to sensitize lymphoid tumor cells $[6,7]$ to the PARP inhibitor olaparib, and sensitivity to gastric cell lines was also suggested to be due to low levels of ATM expression [10]. We assessed the concordance in ATM IHC between preoperative endoscopic biopsy or metastatic tumor samples and whole tissue or primary tumor samples in two independent cohorts. Our study showed that ATM negativity was $13.1 \%$ in biopsies; $13.9,15.1$, and $16.0 \%$ in TMAs, and $15.9 \%$ in whole tissue samples of the gastrectomy cohort, and $21.4 \%$ in primary 
Table 6. Concordance of ATM IHC among biopsy (B), and primary (P) and metastatic tumors (M) from the same gastric cancer patients $(\mathrm{n}=591)$

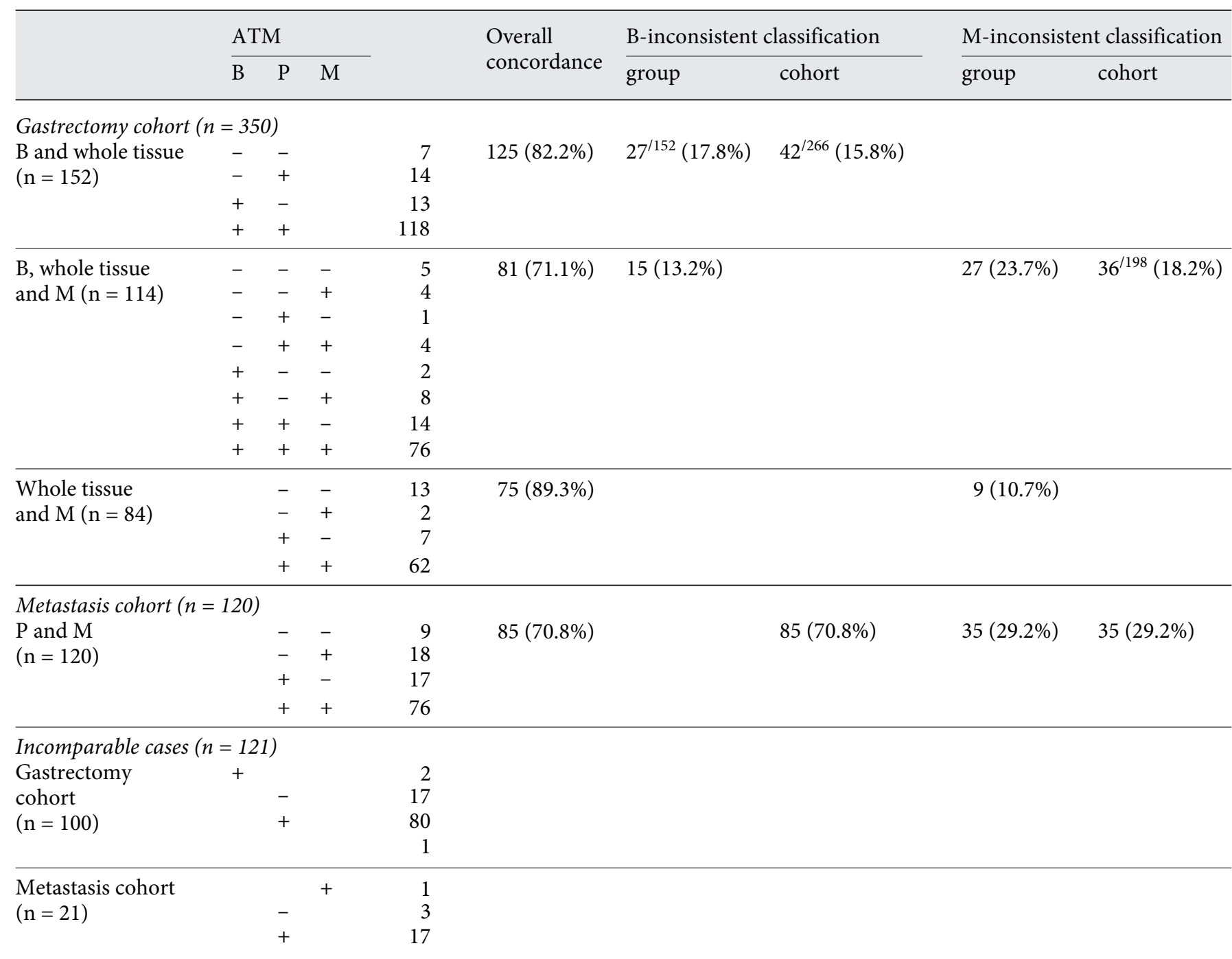

- = ATM negative; + = ATM positive. Numbers which differed from the number given in the first column were given as superscripts.

Table 7. Comparison of ATM IHC, HER2 FISH and HER2 IHC in 3 TMAs from different areas of primary gastric cancers

\begin{tabular}{llll}
\hline & ATM loss by IHC & HER2 overexpression by IHC & HER2 amplification by FISH \\
\hline One or 2 areas (discordant) & $54(14.2 \%)$ & $47(14.5 \%)$ & $8(2.5 \%)$ \\
All 3 areas (concordant) & $30(7.9 \%)$ & $58(17.8 \%)$ & $27(8.3 \%)$ \\
None of 3 areas & $296(77.9 \%)$ & $220(67.7 \%)$ & $290(89.2 \%)$ \\
Discordant/concordant target detection & 1.80 & 0.82 & 0.30 \\
Intraclass correlation & 0.604 & 0.767 & 0.904 \\
\hline Total & 380 & 325 & 325 \\
\hline
\end{tabular}


tumor and $21.5 \%$ in metastatic tumor samples of the metastasis cohort. $\kappa$ coefficients were 0.341 for biopsy, 0.415 for metastatic tumor in the gastrectomy cohort, 0.153 for metastatic tumor in the metastasis cohort, 0.387 for synchronous metastatic tumor and 0.065 for asynchronous metastatic tumor. This suggests that there is significant temporal variation in results over and above spatial variation. Therefore, it is unlikely to be useful as baseline treatment for metastatic disease on the basis of primary tumor measurement of ATM by IHC.

Our study showed that ATM IHC had far lower concordance than those of previously reported tumor suppressor proteins including $\mathrm{pRb}$ [12] and E-cadherin [13]. In our study, the frequency of ATM negativity was found to be lower in biopsy than in whole tissue samples. The observation of lower negativity in biopsy samples is the opposite of what would be expected if discordance was due to the quantity of sample and in contrast to the results of previous HER2 heterogeneity studies [20] where 10 of 54 in biopsies were HER2 $3+$ and 7 of 54 gastrectomy specimens were HER2 $3+$. In terms of tissue quality, biopsies may have better antigen preservation than resection specimens due to the smaller size and more rapid complete formalin penetration.

One possible explanation for the fact that gastric biopsies are not representative of ATM loss is the heterogeneity of the molecular mechanism underlying ATM deficiency in gastric carcinoma. The ATM gene is very large, spanning a genomic region of $150 \mathrm{~kb}$ that contains 66 exons with a coding sequence of $91,668 \mathrm{bp}$. Mutations are found in every exon without hot spots and consist of mostly truncation and splice mutations (85\%) with the minority being missense mutations (15\%) in various cancers [21]. The gene encodes a $350-\mathrm{kDa}$ protein belonging to the phosphatidylinositol-3 kinase family, which has multiple functions including sensing and signaling genome damage resulting from ionizing radiation or chemical carcinogen exposure and activating cell-cycle check points, DNA repair and apoptosis-related proteins including p53. Using denaturing high-performance liquid chromatography to detect ATM gene mutations, Zhang et al. [8] found 11 ATM sequence variants in 5 of 13 gastric cancer cell lines and 2 of 30 cases in tissue specimens. Seven point mutations, 1 deletion mutation and 4 accompanying amino acid changes were identified in gastric cancer cell lines and human gastric cancer tissues. Kang et al. [9] reported that 75\% (30 of 40 cases), 65\% (26 of 40 cases) and $65 \%$ (65 of 40 cases) of gastric cancers showed decreased expression of mRNA, protein and phosphorylated protein of the ATM gene, respectively.

Concordance of ATM in Gastric Cancer
Although more than 100 mutations have been identified so far that are expected to inactivate the ATM protein by truncation or large deletions in various cancers [22], the cause of protein loss and the specific molecular alterations in gastric cancer have not been fully elucidated. The exact nature and timing of any underlying genetic change in the tumor are unknown, and could account for the significant spatial and temporal heterogeneity in IHC staining observed.

In previously published studies, the concordance in HER2 between needle core biopsy and subsequent excisional biopsy of the same tumor in breast cancer was greater than 96 [23] or 95\% [15], respectively. However, intratumoral heterogeneity of HER2 amplification in gastric cancer tissue [16] as well as in breast cancer tissue [24-26] has been reported. Intratumoral heterogeneity was the main reason for the discordant results between IHC and FISH or between endoscopic biopsy and excisional tumor specimens [27]. Heterogeneity of HER2 overexpression/amplification, which is a more frequent event in gastric adenocarcinoma than in breast cancer, can be present with a variety of patterns: heterogeneity of HER2 expression varying from $1+$ to $3+$ in the same tumor, areas of $3+$ in a component of tumor morphologically different from the adjacent negative adenocarcinoma or areas of $3+$ staining in a totally morphologically homogeneous adenocarcinoma [28].

The current study showed low concordance between endoscopic biopsy or metastatic tumor samples and whole tissue sections using $90 \%$ negative cells as the criterion. Changing the cutoff for ATM loss from 90 to $80 \%$ negative cells altered the ATM negativity, sensitivity, specificity and agreement coefficients in each sample, but the $90 \%$ negative cell criterion resulted in better concordance. This suggests that the quantitative modification of IHC scoring could play an important role in the representation of molecular heterogeneity. However, the use of stricter criteria increases the concordance and results in the submission of less heterogeneous cases for treatment. In general, the amount of tissue required for sampling to achieve an accurate representation of the entire tumor is important [25]. Recently, Tolles et al. [29] reported that more heterogeneous markers require a larger number of $\times 20$ fields to estimate a representative measurement of expression. They showed that 8 fields of $\times 20$ are required for the estrogen receptor, 5 fields for HER2 and 14 for MAP-tau, because MAP-tau is a more heterogeneous marker. If a biomarker measurement is to help treatment decisions then it must be able to be made consistently and deliver a result relevant to disease at the time of the 
decision. In model systems, there is a body of evidence that suggests ATM as a candidate marker for the treatment with PARP inhibitors $[6,7,30]$. We first demonstrated that the IHC assay for gastric cancer samples was robust and reproducible by comparing data produced on a common sample set by two independent laboratories. However, in gastric cancer, we have also found that measurement of ATM protein by IHC is subject to significant discordance across multiple sample types and even greater discordance between primary and asynchronous metastatic samples from the same patient. Furthermore, our data suggest that this discordance cannot be solved by modifying classification thresholds. Further work will be necessary to determine if classification may be made more consistent by multiple sampling such as recommended for testing of HER2 expression in gastric tissue.
For example, 7-8 biopsies are recommended to be taken to provide a reliable HER2 result for treatment decision making in HercepTest ${ }^{\mathrm{TM}}$ label (http://www.dako.com/uk/ ar39/p101510/prod_products.htm).

Our study suggests that such sampling would need to be performed at the time of any treatment decision. These observations are gastric cancer specific and are not generally applicable to other tumor types, such as the head and neck, where the underlying genetic lesions in ATM are better understood.

\section{Acknowledgments}

This work was supported by AstraZeneca.

\section{References}

1 Parkin DM, Bray F, Ferlay J, Pisani P: Global cancer statistics, 2002. CA Cancer J Clin 2005;55:74-108.

$\checkmark 2$ Lee JH, Paull TT: Activation and regulation of ATM kinase activity in response to DNA double-strand breaks. Oncogene 2007;26: 7741-7748.

-3 de Murcia JM, Niedergang C, Trucco C, Ricoul M, Dutrillaux B, Mark M, Oliver FJ, Masson M, Dierich A, LeMeur M, Walztinger C, Chambon P, de Murcia G: Requirement of poly(ADP-ribose) polymerase in recovery from DNA damage in mice and in cells. Proc Natl Acad Sci USA 1997;94:73037307.

4 Gelmon KA, Tischkowitz M, Mackay H, Swenerton K, Robidoux A, Tonkin K, Hirte H, Huntsman D, Clemons M, Gilks B, Yerushalmi R, Macpherson E, Carmichael J, Oza A: Olaparib in patients with recurrent high-grade serous or poorly differentiated ovarian carcinoma or triple-negative breast cancer: a phase 2, multicentre, open-label, non-randomised study. Lancet Oncol 2011; $12: 852-861$.

5 Schaffner C, Idler I, Stilgenbauer S, Döhner $\mathrm{H}$, Lichter P: Mantle cell lymphoma is characterized by inactivation of the ATM gene. Proc Natl Acad Sci USA 2000;97:2773-2778.

6 Williamson CT, Muzik H, Turhan AG, Zamo A, O’Connor MJ, Bebb DG, Lees-Miller SP: ATM deficiency sensitizes mantle cell lymphoma cells to poly(ADP-ribose) polymerase-1 inhibitors. Mol Cancer Ther 2010; 9:347-357.

7 Weston VJ, Oldreive CE, Skowronska A, Oscier DG, Pratt G, Dyer MJS, Smith G, Powell JE, Rudzki Z, Kearns P, Moss PAH, Taylor AMR, Stankovic T: The PARP inhibitor olaparib induces significant killing of
ATM-deficient lymphoid tumor cells in vitro $>13$ Boone J, Hillegersberg R, Diest PJ, Offerhaus and in vivo. Blood 2010;116:4578-4587.

8 Zhang L, Jia G, Li W-M, Guo R-F, Cui J-T, Yang L, Lu Y-Y: Alteration of the ATM gene occurs in gastric cancer cell lines and primary tumors associated with cellular response to DNA damage. Mutat Res 2004;557:41-51.

$>9$ Kang B, Guo RF, Tan XH, Zhao M, Tang ZB, Lu YY: Expression status of ataxia-telangiectasia-mutated gene correlated with prognosis in advanced gastric cancer. Mutat Res 2008;638:17-25.

10 Guo X, Cheng W, Bai Y, Ni X-Z, Shen D, Zhang S, Xie L, Knights C, Lau A, O’Connor $M$, Yin X, Warford A, Gu Y: ATM deficiency sensitizes gastric cancer cells to the PARP inhibitor olaparib. Mol Cancer Ther 2009; 8:(Meeting Abstract Supplement)B42.

$\checkmark 11$ Hammond MEH, Hayes DF, Dowsett M, Allred DC, Hagerty KL, Badve S, Fitzgibbons PL, Francis G, Goldstein NS, Hayes M, Hicks DG, Lester S, Love R, Mangu PB, McShane L, Miller K, Osborne CK, Paik S, Perlmutter J, Rhodes A, Sasano H, Schwartz JN, Sweep FCG, Taube S, Torlakovic EE, Valenstein P, Viale G, Visscher D, Wheeler T, Williams RB, Wittliff JL, Wolff AC: American Society of Clinical Oncology/College of American Pathologists guideline recommendations for immunohistochemical testing of estrogen and progesterone receptors in breast cancer. J Clin Oncol 2010;28:27842795.

12 Hoos A, Urist MJ, Stojadinovic A, Mastorides S, Dudas ME, Leung DH, Kuo D, Brennan MF, Lewis JJ, Cordon-Cardo C: Validation of tissue microarrays for immunohistochemical profiling of cancer specimens using the example of human fibroblastic tumors. Am J Pathol 2001;158:1245-1251. GJA, Borel Rinkes IHM, Ten Kate FJW: Validation of tissue microarray technology in squamous cell carcinoma of the esophagus. Virchows Arch 2008;452:507-514.

14 Chivukula M, Bhargava R, Brufsky A, Surti U, Dabbs DJ: Clinical importance of HER2 immunohistologic heterogeneous expression in core-needle biopsies vs resection specimens for equivocal (immunohistochemical score 2+) cases. Mod Pathol 2008; 21:363-368.

15 D’Alfonso T, Liu YF, Monni S, Rosen PP, Shin SJ: Accurately assessing HER-2/NEU status in needle core biopsies of breast cancer patients in the era of neoadjuvant therapy: emerging questions and considerations addressed. Am J Surg Pathol 2010;34: 575-581.

16 Kim MA, Lee H-J, Yang H-K, Bang Y-J, Kim WH: Heterogeneous amplification of ERBB2 in primary lesions is responsible for the discordant ERBB2 status of primary and metastatic lesions in gastric carcinoma. Histopathology 2011;59:822-831.

17 Greene FL, Page DL, Fleming ID, Fritz AG, Balch CM, Haller DG, Morrow M: AJCC Cancer Staging Manual. New York, Springer, 2002, pp 99-106.

18 Landis JR, Koch GG: The measurement of observer agreement for categorical data. Biometrics 1977;33:159-174.

19 Catalano V, Labianca R, Beretta GD, Gatta G, de Braud F, Van Cutsem E: Gastric cancer. Crit Rev Oncol Hematol 2009;71:127-164.

20 Lee S, de Boer WB, Fermoyle S, Platten M, Kumarasinghe MP: Human epidermal growth factor receptor 2 testing in gastric carcinoma: issues related to heterogeneity in biopsies and resections. Histopathology 2011;59:832-840. 
21 Buzin CH, Gatti RA, Nguyen VQ, Wen CY, Mitui M, Sanal O, Chen JS, Nozari G, Mengos A, Li X, Fujimura F, Sommer SS: Comprehensive scanning of the ATM gene with DOVAM-S. Hum Mutat 2003;21:123131.

-22 Savitsky K, Sfez S, Tagle DA, Ziv Y, Sartiel A, Collins FS, Shiloh Y, Rotman G: The complete sequence of the coding region of the ATM gene reveals similarity to cell cycle regulators in different species. Hum Mol Genet 1995;4:2025-2032.

23 Apple SK, Lowe AC, Rao PN, Shintaku IP, Moatamed NA: Comparison of fluorescent in situ hybridization HER-2/neu results on core needle biopsy and excisional biopsy in primary breast cancer. Mod Pathol 2009;22: 1151-1159.
4 Brunelli M, Manfrin E, Martignoni G, Miller K, Remo A, Reghellin D, Bersani S, Gobbo S, Eccher A, Chilosi M, Bonetti F: Genotypic intratumoral heterogeneity in breast carcinoma with HER2/neu amplification: evaluation according to ASCO/CAP criteria. Am J Clin Pathol 2009;131:678-682.

25 Moeder CB, Giltnane JM, Harigopal M, Molinaro A, Robinson A, Gelmon K, Huntsman D, Camp RL, Rimm DL, American Society of Clinical Oncology, College of American Pathologists: Quantitative justification of the change from $10 \%$ to $30 \%$ for human epidermal growth factor receptor 2 scoring in the American Society of Clinical Oncology/ College of American Pathologists guidelines: tumor heterogeneity in breast cancer and its implications for tissue microarray based assessment of outcome. J Clin Oncol 2007;25:5418-5425.

26 Bernasconi B, Chiaravalli AM, Finzi G, Milani K, Tibiletti MG: Genetic heterogeneity in HER2 testing may influence therapy eligibility. Breast Cancer Res Treat 2012;133:161168.
27 Yang J, Luo H, Li Y, Li J, Cai Z, Su X, Dai D, Du $\mathrm{W}$, Chen T, Chen M: Intratumoral heterogeneity determines discordant results of diagnostic tests for human epidermal growth factor receptor (HER) 2 in gastric cancer specimens. Cell Biochem Biophys 2012;62:221-228.

28 Albarello L, Pecciarini L, Doglioni C: HER2 testing in gastric cancer. Adv Anat Pathol 2011;18:53-59.

29 Tolles J, Bai Y, Baquero M, Harris LN, Rimm DL, Molinaro AM: Optimal tumor sampling for immunostaining of biomarkers in breast carcinoma. Breast Cancer Res 2011;13:R51.

30 Loser DA, Shibata A, Shibata AK, Woodbine LJ, Jeggo PA, Chalmers AJ: Sensitization to radiation and alkylating agents by inhibitors of poly(ADP-ribose) polymerase is enhanced in cells deficient in DNA double-strand break repair. Mol Cancer Ther 2010;9:1775-1787. 